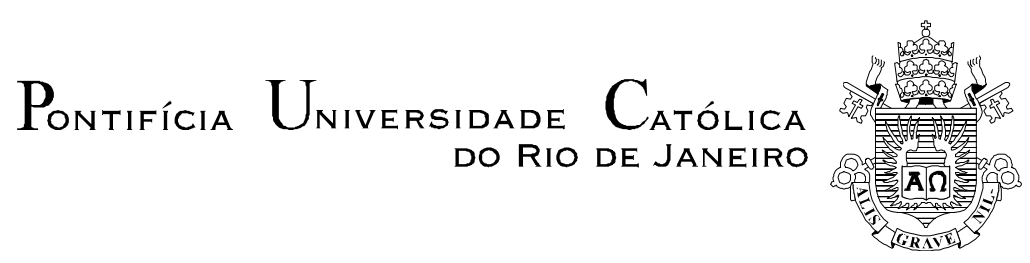

Antonio Henrique de Castilho Gomes

\title{
A [re]configuração do discurso do samba
}

Tese apresentada ao programa de Pós-graduação em Letras da PUC-Rio como requisito parcial para a obtenção do título de Doutor em Letras.

Orientador: Prof. Julio Cesar Valladão Diniz 


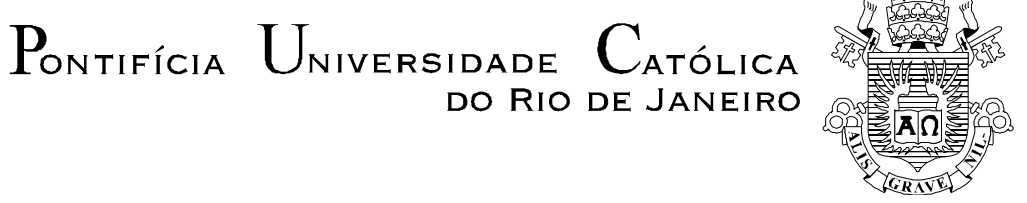

\section{Antonio Henrique de Castilho Gomes}

\section{A [re]configuração do discurso do samba}

Defesa de Tese apresentada como requisito parcial para obtenção do grau de Doutor pelo programa de Pós-Graduação em Letras do Departamento de Letras do Centro de Teologia e Ciências Humanas da PUCRio. Aprovada pela Comissão Examinadora abaixo assinada.

Profo. . Júlio Cesar Valladão Diniz

Orientador

Departamento de Letras - PUC-Rio

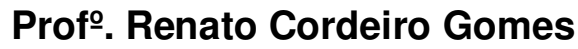

Departamento de Letras - PUC-Rio

Profa. Stella Teresa Aponte Caymmi

Profo. Frederico Augusto Liberalli de Goes

UFRJ

Alexandre Graça Faria

UFJF

Profa. Denise Berruezo Portinari

Coordenadora Setorial do Centro de Teologia

e Ciências Humanas - PUC-Rio

Rio de Janeiro, 11 de abril de 2012. 
Todos os direitos reservados. É proibida a reprodução total ou parcial do trabalho sem autorização da universidade, do autor e do orientador.

\section{Antonio Henrique de Castilho Gomes}

Professor graduado em Museologia pela Universidade do Rio de Janeiro e em História pela Universidade Federal Fluminense, Mestre em Letras pela Pontifícia Universidade Católica do Rio de Janeiro, atuante na rede privada de ensino médio.

Ficha Catalográfica

Gomes, Antonio Henrique de Castilho

A [re]configuração do discurso do samba / Antonio Henrique de Castilho Gomes ; orientador: Julio Cesar Valladão Diniz. - 2012.

$178 \mathrm{f}$. ; $30 \mathrm{~cm}$

Tese (doutorado)-Pontifícia Universidade Católica do Rio de Janeiro, Departamento de Letras, 2012.

Inclui bibliografia

1. Letras - Teses. 2. Samba. 3. Escola de samba. 4. Carnaval. 5. Desfile. 6. Cultura popular. 7. Indústria cultural. I. Diniz, Julio Cesar Valladão. II. Pontifícia Universidade Católica do Rio de Janeiro. Departamento de Letras. III. Título.

CDD: 800 
Aos meus verdadeiros amores, minha esposa Ursula e meus filhos João Pedro e Bernardo, que dão sentido a minha vida. 
A meus pais Fernando e Carmem (in memorian), que muito se sacrificaram para que eu pudesse chegar aonde cheguei. 


\section{Agradecimentos}

Este espaço é reservado para que, de alguma forma, eu possa retribuir toda a ajuda que recebi ao longo do processo de construção desta tese. Devo muitas coisas à muitas pessoas, por isso peço desculpas se algum nome for esquecido. O número de pessoas que de forma relevante contribuíram para a formação da minha vida é muito maior de que os aqui listados.

Em primeiro lugar quero agradecer ao meu orientador e amigo Júlio Diniz, com quem tive a honra de conviver os últimos oito anos, por todo 0 comprometimento, toda a disponibilidade a mim dedicada, e pelos proveitosos encontros informais. Incluo aqui também sinceros agradecimentos aos professores Karl Erik, Ana Paula Kiffer, Heidrun Krieger, que estiveram presentes durante meu percurso. Não posso esquecer-me de mencionar a fantástica Chiquinha, sempre pronta para resolver todos nossos problemas. Agradeço ainda à PUC-Rio, pelo auxílio concedido, sem o qual este trabalho não poderia ser realizado.

Sou muito grato também às amizades que construí na PUC e que me foram de grande valia, nos informais papos acontecidos no "Pires" e em tantos outros lugares. Em especial, gostaria de destacar: Stella Caymmi, Ana Paula de Oliveira, Leinimar Pires, Marcela, Daniel, Mauro e tantos outros que me fogem a memória. 
Gostaria de agradecer também aos meus "padrinhos", que me introduziram no mundo do samba, em especial Jandyr Antunes, Jayminho, Paulinho Careca, Maurício “Pipa”, Alexandre Brittes, Hiram Araujo e a meu tio Paulo Bayde.

Também sou muito grato aos companheiros de profissão que muito colaboraram ao longo desta jornada, com conselhos, paciência e acima de tudo cumplicidade: Nelson Oliveira, Waldyr Leal, Perivaldo, Nelson Ricardo, Celeste. Agradeço também a valorosa contribuição dos amigos, professores, gestores e meus queridos alunos da Escola SESC de Ensino Médio que muito me incentivaram e fortaleceram em especial a grande figura de Eduardo Fillipe, com quem pude trocar muitas experiências, que me foram de grande valia. Não poderia negligenciar um agradecimento especial a Rodrigo Peixoto, pelo gigantesco esforço dedicado a revisão desta tese.

Deixo para o final o agradecimento mais afetuoso. Agradeço a minha família. Meus primos, minha irmã Carla, meus cunhados e sobrinhos, meus sogros, minha madrinha e segunda mãe e principalmente minha esposa Ursula à quem muito amo e a meus filhos João Pedro e Bernardo, que souberam abrir mão do marido e pai neste complexo caminho que me trouxe até aqui. Amo-os profundamente. 


\section{Resumo}

Gomes, Antonio Henrique de Castilho; Diniz, Júlio Cesar Valladão. A [re]configuração do discurso do samba. Rio de Janeiro, 2012. 178p. Tese de Doutorado - Departamento de Letras, Pontifícia Universidade Católica do Rio de Janeiro.

Esta tese consiste em uma análise crítica da reconfiguração do discurso do samba, entendendo a expressão samba não apenas como gênero musical, mas como um evento que reúne o samba enredo, seu par natural na escola de samba, e o produto final desta relação, o desfile. Entendendo tal fenômeno como uma manifestação da cultura popular, este trabalho objetiva analisar as diversas estratégias utilizadas pelo samba a fim de se transformar, mantendo-se hegemônico no cenário cultural brasileiro. Para tanto, esta tese debruça seu olhar sobre alguns elementos e momentos históricos que foram fundamentais para a consolidação do caráter dominante do samba. Em primeiro lugar, buscase comprovar o espaço de fala do subalterno proporcionado pela força da configuração do samba no espaço cultural brasileiro. No segundo momento, fazse uma análise das relações existentes entre o samba, o sambista, entendido aqui de forma mais abrangente possível, e a indústria cultural. Por fim, busca-se compreender de que forma se constrói o discurso do samba hoje em dia, que relações são tecidas e de que formas elas são utilizadas para garantir o objetivo fundamental do samba que é permanecer como principal manifestação de cultura popular brasileira.

\section{Palavras-chave}

Samba; escola de samba; carnaval; desfile; cultura popular e indústria cultural. 


\section{Abstract}

Gomes, Antonio Henrique de Castilho; Diniz, Júlio Cesar Valladão. The [re] configuring samba speech. Rio de Janeiro, 2012. 178p. Doctor Thesis Departamento de Letras, Pontifícia Universidade Católica do Rio de Janeiro.

This thesis consists of a review of the reconfiguration of the discourse of samba, samba understand the expression not only as musical genre, but as an event that brings together the samba enredo, her natural pair in the school of samba, the end product of this relationship, the carnival parade. Understanding this phenomenon as a manifestation of popular culture, this work aims to analyze the different strategies used by Samba to become, keeping the hegemonic cultural scene in Brazil. To this end, this thesis focuses its look on some elements and historical moments that were essential for the consolidation of the dominant character of samba. First, it seeks to prove the speech of the subaltern space provided by the force of the samba configuration space of Brazilian culture. In the second moment, it is an analysis of the relationship between samba, sambista, understood more broadly as possible, and cultural industry. Finally, it seeks to understand how speech is constructed of samba nowadays, what relationships are woven and in what ways they are used to ensure the fundamental objective of samba that is to remain as the main manifestation of Brazilian popular culture.

\section{Keywords}

Samba; school of samba; carnival; carnival parade; popular culture and cultural industry. 


\section{Sumário}

1. Introdução 11

2. O samba e suas falas 18

2.1.O samba como espaço de fala 20

2.2. Samba e cultura popular 27

3.O samba, o sambista e a indústria cultural 45

3.1.O samba 47

3.2.O sambista 60

3.3.A indústria cultural $\quad 73$

4.A reconfiguração do discurso do samba $\quad 87$

4.1.As novas exigências do concurso das escolas de samba do Rio de Janeiro 88

4.2.As novas superescolas de samba 104

4.3.O novo conceito de comunidade: entre o afeto e a territorialidade 116

5. Conclusão 126

6. Referências

6.1. Livros e periódicos 132

6.2.Sites 143

7. Anexos

7.1. Entrevistas concedidas ao autor

7.1.1. Jandyr Antunes e Jaime da Vila 147

7.1.2. Alexandre Brittes 153

7.1.3. Hiram Araújo 156

7.2. Entrevistas retiradas de periódicos - recurso eletrônico

7.2.1. Fernando Pamplona, o revolucionário tradicional 158

7.2.2. Fernando Pamplona - Carnavalesco 161 